\title{
A construção de consensos como instrumento eficaz de gestão de conflitos socioambientais
}

\section{Consensus building as an effective tool of environmental conflict management}

\author{
Alessander Wilckson Cabral Sales* \\ Vladia Pinto Vidal de Oliveira*
}

\section{Resumo}

Métodos consensuais de resolução de litígios são mecanismos utilizados para a decomposição de conflitos específicos, como alternativas ao manejo de técnicas tradicionais, como a judicialização. Negociação, mediação e arbitragem estão entre os métodos mais referidos e praticados no Brasil. Estudos recentes sistematizaram o instituto da construção de consensos, como um novo intrumento voltado para solução negociada de conflitos envolvendo múltiplas partes, como os de natureza socioambeintal. Este estudo demonstra a eficiência da utilização do mecanismo de construção de consensos para a identificação, composição e solução de conflitos socioambientais, visto que aprimora o processo da tomada de decisões que resulta na formulação de políticas públicas, cujo objetivo é equilibrar o crescimento econômico e proteção do meio ambiente.

Palavras-chave: Mediação. Construção de consenso. Questões ambientais.

\section{Abstract}

Consensual methods of dispute resolution mechanisms are used for the composition of specific conflicts, as alternatives to traditional management techniques with legalization. Negotiation, mediation and arbitration are among the most mentioned methods and practiced in Brazil. Recent studies systematized the Institute of building consensus, as a new instrument aimed at negotiated solution of conflicts involving multiple parties, such as socioambeintal nature. This study demonstrates the efficiency of the use of consensus-building mechanism for the identification, composition and solution of environmental conflicts, in that it enhances the process of decision making resulting in the formulation of public policies aimed at balancing economic growth and environmental protection.

Keywords: Mediation. Consensus. Environmental issues.

\section{Introdução}

A percepção sobre a complexidade dos conflitos e a necessidade de sua adequada administração indicam a importância de realização de estudos sobre meios eficazes de solução de controvérsias de variadas naturezas. A construção de consensos é apresentada como mecanismo autônomo, inovador, de

Mestrado em Direito Público pela Universidade de Fortaleza (2004). Procurador da República do Ministério Público Federal do Estado do Ceará. Fortaleza - CE- Brasil. E-mail: alessandersales@hotmail.com.

Doutorado em Engenharia Agronômica (2002) no Programa Agricultura e Meio Ambiente em Zonas Semiáridas Universidade de Almería (UAL). Professora Associada III do Departamento de Geografia da Universidade Federal do Ceará e pesquisadora do CNPq. Mestrado em Agronomia (Solos e Nutrição de Plantas). Cursos de Pós-graduação em Gerenciamento Costeiro (Labomar/UFC) e dois Internacionais com bolsa da ONU (Argentina e Rússia) na temática de Desertificação. Coordenadora do Doutorado em Desenvolvimento e Meio Ambiente (PRODEMA) em Rede (UFC/UFPI/UFRN/UFPB/UFPE/FUFS/UESC). Editora Chefe na Revista REDE - PRODEMA. Coordenadora do Programa de Mobilidade Internacional AULP/CAPES-UFC/UNIC-CV. Consultora Adhoc da Revista Mercator, Ambiente \& Água e Ambiente e Sociedade. Fortaleza - CE Brasil. E-mail: vladia.ufc@gmail.com. 
solução de litígios, que preza pelo diálogo, inclusão, consenso, eficácia, e que identifica os conflitos como sistêmicos, possibilitando a construção de soluções pacíficas e adequadas a essa complexidade.

Os conflitos socioambientais apresentam uma complexidade que necessita de inovações para sua adequada compreensão, composição e solução. O conceito de meio ambiente é complexo, requerendo a compreensão da interação do meio ambiente natural, artificial e cultural. Os conflitos decorrentes da relação socioambiental envolvem múltiplas partes, o que dificulta a satisfação de todos quando a decisão de uma disputa advém de imposições monocráticas verticalizadas. Por todos esses nuances, aponta-se a construção de consensos como mecanismo adequado de gestão desses conflitos na medida em que sua utilização poderá resultar em uma maior discussão e em entendimento adequado e profundo dos problemas geradores de dissensos, com a efetiva possibilidade de sua superação pacífica através de uma construção cooperativa da melhor decisão possível a ser aplicada em uma situação conflituosa concreta.

\section{Os conflitos socioambientais}

Conflitos de natureza socioambiental estarão cada vez mais presentes no dia a dia das interações sociais, principalmente em razão do aumento constante da competição pelo acesso aos recursos naturais finitos.

Não há dúvida de que os regimes econômicos prevalentes no mundo, de matriz capitalista, na medida em que produzem mercadorias em larga escala, estimulam o aumento da pressão sobre a utilização de ecossistemas, pois a produção crescente também necessita de um alargamento de sua base material, sendo a apropriação de recursos naturais uma das formas mais eficientes de prover esse crescimento econômico.

A tendência, portanto, é a potencialização de conflitos entre grupos sociais com visões distintas sobre os valores postos em direta contradição, consubstanciada em diferentes formas de entender a relação entre o crescimento econômico e a preservação ambiental, pois, como acentuado por Martínez Alier (2007), diversos atores esgrimem variados discursos de valoração quando se trata de conflitos socioecológicos, todos com uma linguagem socialmente válida. Há quem insista no predomínio do crescimento econômico e na necessidade de aliviar a pobreza não por meio da redistribuição, mas do crescimento a qualquer custo; como, por outro lado, existem os que apelam para o discurso dos direitos humanos.

Assim, há espaço para a potencialização de conflitos que têm por objeto bens ambientalmente relevantes. Na verdade, esses conflitos têm natureza distributiva, devendo-se compreender que se estabelecem sobre os padrões sociais, espaciais e temporais de acessibilidade aos benefícios obtidos dos recursos naturais e aos serviços proporcionados pelo ambiente como um sistema de suporte da vida.

Essa distribuição é definida por determinantes naturais, como o clima, topografia, padrões pluviométricos, jazidas de minerais, qualidade do solo, etc., outras vezes por critérios sociais, culturais, econômicos, políticos e tecnológicos. A questão é distributiva porque insere em seu âmbito a noção de injustiça distributiva, onde a competição determina, de forma desigual, o acesso e a titularização de bens ambientais.

Entendem-se, assim, por conflitos socioambientais, aqueles que são determinados por diversas visões sobre a valoração que se deve dar a bens ambientalmente relevantes. Ademais, essa contradição valorativa por si só não é bastante, devendo estar presente a potencialidade de que venha a resultar em escassez dos recursos naturais, provocados pelas atividades socioeconômicas que causam degradação ao ambiente natural.

Assim, é a escassez ocasionada pela forma de utilização da natureza que determina os desequilíbrios sociais, econômicos e ambientais. Quando esses desequilíbrios ocorrem, os conflitos socioambientais se instalam e, se não forem devidamente compostos e superados, tendem a se acirrar, gerando consequências negativas ao equilíbrio natural das relações sobre as quais foram produzidos. 
Os conflitos socioambientais podem ser sintetizados como disputas entre grupos sociais provenientes de distintas formas de relações por eles mantidas com seu meio natural.

Há três dimensões básicas a serem ponderadas no entendimento e na análise dos conflitos socioambientais: o mundo biofísico e os ciclos naturais; o mundo humano e suas estruturas sociais; e o relacionamento dinâmico e interdependente entre os dois mundos. Portanto, conflitos socioambientais são conflitos sociais decorrentes de uma disputa sobre a distribuição e a utilização de bens ambientais (LITTLE, 2002).

Na perspectiva ora desenvolvida, é importante definir o foco, os elementos de caracterização e os atores envolvidos em um determinado conflito social para que este, em face dessas especificidades, possa vir a ser definido como de natureza socioambiental.

Com relação ao foco, destacam-se como socioambientais os conflitos que incidem sobre: 1) o controle sobre os recursos naturais, consistente no domínio sobre o acesso, a distribuição ou a utilização de bens ambientais; 2) os impactos sociais e ambientais gerados pela ação humana e natural, surgidos a partir de constatação da ocorrência de danos ambientais a ecossistemas e 3) o uso de conhecimentos ambientais, que incidem sobre situações de utilização e novas tecnologias e sobre o patrimônio cultural, tradicional, artístico, místico, etc.

Quanto aos elementos de definição do conflito socioambiental, enumeram-se: 1) complexidade e interdependência, pois múltiplos fatores (econômicos, sociais, políticos, urbanísticos, etc.) estão diretamente relacionados a esse tipo de conflito; 2) especificidade, pois cada conflito desta natureza é único, não se confundindo com outros já ocorridos; 3) continuidade e evolução, na medida em que não são estanques, evoluindo, positiva ou negativamente, com o tratamento que lhe for conferido; 4) cenário, significando que são conflitos que inter-relacionam ambientes; 5) informação, sempre exigível em maior escala em face do elemento complexidade; 6) incerteza científica e riscos, decorrente da indefinição técnica e dos riscos naturais e sociais ante a imprevisibilidade da consequência de cada ação; 7) interesse público, pois tais conflitos são de ordem pública já que o meio ambiente é patrimônio de todos, ou seja, público; 8) interesses não representados, por falta de grupos que o titularizem ou ainda por sua natureza intergeracional; 9) multiplicidade de atores e de âmbitos decisórios, pois vários atores atuam, às vezes, com sobreposição, e ainda existem diversas instâncias de tomada de decisão (administrativa, judicial, política e social).

Socioambientais, ainda, segundo a RED MESOAMERICANA (1999) são os conflitos cujus atores podem ser: 1) coletivos não homogêneos, que defendem direito difuso e, assim, de todos, sem titularização imediatamente referida a indivíduos ou grupos; 2) detentores de diferentes níveis de conhecimento, em face da fragmentação desses interesses no campo da informação e 3) detentores de diferentes graus de recursos e poder, pois pertencentes a esferas econômicas, sociais e culturais não uniformes.

Existe ainda uma consideração de ordem espacial que não pode ser desprezada, pois, ao cabo, os conflitos socioambientais são sempre, na verdade, estabelecidos sobre um dado território que concentra bens ambientais significativos para os diversos atores envolvidos em situações distintas de interesse na sua utilização. São, assim, conflitos de grupos humanos que reivindicam essas terras como seu território de moradia e vivência, portanto, os conflitos têm dimensões políticas, sociais e jurídicas. Cada agente social tem sua forma de adaptação, ideologia e modo de vida que entra em choque com as formas dos outros grupos, dando assim a dimensão social e cultural do conflito socioambiental.

A complexidade dos conflitos socioambientais demonstra que muitos, especialmente os vivenciados no Brasil, envolvem, em certo grau, atos violentos e são decorrentes da má-administração dessas questões. Pelo desconhecimento da legislação, pela falta de compromisso com o desenvolvimento sustentável, pela arbitrariedade, pelo desprezo para com o diálogo inclusivo, muitas instituições públicas e privadas demonstram profundo despreparo para desenvolver atividades de acordo com a legislação ambiental, ou para resolver questões de forma participativa, inclusiva e dialogada.Surgido o conflito ambiental, seu acirramento leva as partes a buscarem sua resolução, quase sempre, numa perspectiva judicial. 
O exercício da jurisdição, atividade típica de composição de conflitos no Judiciário, é desenvolvido sob a lógica da litigiosidade resistida. Uma parte, julgando-se titular de um direito cuja fruição está sendo obstada, dificultada, ou condicionada, pela ação ou pela omissão de outra parte, provoca o Juiz para que este, na condição de terceiro imparcial, possa dizer se a resistência, ou os condicionamentos alegados, existem e, se existentes, se são legítimos ou não.

A relação entre as partes é iniciada numa perspectiva adversarial, se desenvolve com essa mesma natureza e produz, em regra, decisões que impõem um comportamento como o único válido na dada situação analisada. O Estado, através do juiz como seu representante, emite pronunciamentos de autoridade, fundados na lei e nas circunstâncias do caso concreto e, assim, bem ou mal, resolve o conflito.

Essa é a forma tradicional de resolução de conflitos, a mais utilizada e manejada pelos interessados no Brasil. Dados oficiais atuais contabilizam a existência, no país, de mais de 100 (cem) milhões de ações judiciais em tramitação no Judiciário, o que equivale a uma média de uma ação para cada dois habitantes. Essa grave situação reforça a percepção de dois sérios problemas: 1) o elevado grau de litigiosidade existente, significando comportamentos sistemáticos de descumprimento das leis e 2) a impossibilidade de qualquer estrutura estatal dar vazão, com respostas adequadas, justas, céleres e socialmente úteis, a esse universo de demandas.

Ante a constatação de que a resolução judicial de conflitos no Brasil caminhava a passos largos para o seu esgotamento, a evolução que podia ser facilmente percebida pela perda progressiva de eficiência na prestação jurisdicional e pela elevação do grau de insatisfação das partes em litígio com as respostas recebidas, foram gradativamente surgindo outras formas de composição de conflitos que, ao contrário da forma tradicional, não apostam na perspectiva adversarial, mas na possibilidade de construção de consensos entre as partes na busca de soluções mais ágeis, focadas nas causas reais, e não meramente aparentes do conflito, bem como na obtenção de decisões mais justas e principalmente mais úteis, ou seja, capazes de promover uma maior pacificação social.

Essas novas técnicas propõem a autocomposição do conflito, ou seja, que as partes em litígio se envolvam diretamente na procura da decisão mais satisfatória, não só para uma delas, mas para todos os envolvidos, conseguindo assim tratar o conflito de forma definitiva, sem a necessidade de que um terceiro imponha uma decisão julgada correta. Ao invés da construção da solução pelo confronto, buscam edificar a superação do conflito pelo consenso.

Essa busca por novas estratégias de decomposição não adversariais de conflitos é um fenômeno mundial que vem evoluindo rapidamente. Segundo Christopher Moore e Peter Woodrow (1999), essa mudança tem como causa a insatisfação com os processos autoritários de tomada de decisão, com custos cada vez mais altos com os processos adversariais do tipo perde-ganha. Além desse fator, destaca-se a expansão das aspirações pela participação democrática em todos os níveis sociais e políticos, no sentido de o indivíduo poder participar ativamente das decisões que dizem respeito à sua própria vida.

Métodos não adversariais de composição de conflitos tem uma relação direta, em termos de eficácia, com a superação de conflitos de natureza socioambiental. Esses, como já visto, são conflitos específicos que, por sua própria natureza, contrapõem interesses construídos a partir de diferentes visões sobre o crescimento econômico e a proteção ambiental.

Pontos de vistas distintos sobre um mesmo problema, embora inicialmente pareçam afastar pessoas, as aproxima em face de um determinado objetivo. O problema não é a divergência de convencimentos, visões e atitudes. O conflito que nasce dessa divergência é normal e próprio da natureza humana, principalmente nas sociedades modernas, sujeitas a um elevado grau de estratificação econômica e social.

O problema é que esse tipo de conflito vem sendo historicamente composto em uma perspectiva adversarial, que se dá pela utilização dos instrumentos clássicos de resolução de disputas, onde se sobressai a judicialização. Assim, as partes envolvidas não abrem mão de suas distintas visões, buscam 
sempre afirmar seus interesses contra os do adversário para, ao final, obterem uma decisão em que um ganha e outro perde.

A forma adversarial não consegue compor adequadamente conflitos socioambientais. Ela não está apta a entender a complexidade desse tipo de conflito, não trabalha com instrumentos procedimentais elaborados para essa conflituosidade metaindividual, não se adequa a sua natureza difusa, diversidade de atores, muito menos promove uma interpretação que situa adequadamente a proteção ambiental como direito humano fundamental quando em contrariedade com outros direitos e interesses.

Dessa forma, a judicialização não produz resultados justos e socialmente úteis e, nesaa relação de perde e ganha, o maior vencido, quase sempre, é o próprio meio ambiente que resta destituído de sua efetiva proteção.

Deve ser realizada uma mudança de paradigma. Superar a cultura adversarial do litígio que trata dos conflitos quase sempre numa perspectiva repressiva, para a criação de uma atmosfera de prevenção de ocorrência de novos conflitos, sendo isso possível somente com a superação da competição através da criação da cooperação.

Basicamente, entende-se por negociação o conjunto de técnicas de composição não adversarial de conflitos. Uma modalidade própria de negociação que pode ser adaptada com maior eficiência aos conflitos socioambientais é a mediação de conflitos, caracterizada pela presença de um terceiro que facilita a adequada compreensão do conflito real pelas partes envolvidas e suas perspectivas possibilidades de superação, ajudando-as a estabelecer a base do consenso final que, superando a conflituosidade entre elas existente, constrói a pacificação social.

Em casos de multiplicidades de atores, identificados pela complexidade do conflito, as técnicas de negociação desenvolvidas pela mediação ganham especificidades, gerando o que se convencionou denominar de procedimento de construção de consensos.

Em experiências inovadoras nos Estados Unidos, o professor Lawrence Susskind apresenta a construção de consenso como mecanismo adequado para solução de conflitos gerados em questões ambientais.

\section{A construção de consenso}

A proposta da construção de consensos vem sendo bastante aplicada para a solução de conflitos que envolvam um número expressivo de pessoas. O consenso buscado não se concretiza na unanimidade, mas na definição de um acordo geral com o qual todos, ou quase todos, possam conviver com satisfação e harmonia.

É um acordo geral alcançado a partir da participação de todos os envolvidos nos conflitos abordados, apresentando a solidariedade como sentimento primordial. Ressalta-se ainda a importância do consenso consciente, ou informado, ou seja, não o que estabelece um acordo no qual as pessoas não sabem ao certo o que decidiram (normalmente resultado de persuasão), mas um acordo discutido, participado, em que as pessoas saibam exatamente o compromisso de cada um.

A teoria da construção do consenso, ideal para processos multipartes, estabelece seis pressupostos fundamentais: 1) em qualquer tomada de decisão em que existam grupos ou organizações representados ou representando outros maiores, necessário se faz que se deixe clara a sua responsabilidade para com os seus representados e para com todas as partes envolvidas; 2) o diálogo entre as partes só deve começar quando todas as pessoas se identificam, expressam sua missão, estabelecem uma agenda de trabalhos e as regras que guiarão as conversações; 3) os grupos devem coletar informações básicas sobre o conflito que todo o grupo entenda como confiáveis (mesmo que interpretem de forma distinta); 4) os grupos devem encontrar soluções que permitam a todos vivenciar uma situação melhor do que se não tivessem alcançado essa solução; 5) quando as pessoas que estão envolvidas diretamente no diálogo 
representam outras pessoas ou grupos, é importante que seja elaborado um esboço do acordo realizado para que essas pessoas avaliem se realmente expressa a satisfação de todos; 6 ) os grupos devem "pensar à frente", buscando prevenir obstáculos que possam surgir na implementação de suas decisões.

Além desses pressupostos, o processo de construção de consensos também deve ser desenvolvido com as seguintes premissas: permitir o reconhecimento das diferenças, a possibilidades das partes se manterem em desacordo, desenvolver uma metodologia de inclusão e perceber e distinguir as posições, os interesses e os valores das partes.

Reconhecer as diferenças entre os atores participantes significa que a riqueza do procedimento vem justamente das diferentes visões sobre o conflito. Esse dissenso inicial não é negativo, ele é natural. Percepções distintas, no entanto, podem ser trabalhadas no processo e, ao final, podem ser ajustadas para formar consensos. O resultado do processo, ou seja, o acordo, é o consenso formado a partir dessa rica diversidade de entendimentos, compreensões e visões do conflito.

No processo de construção e consensos as partes devem ter assegurada a prerrogativa de manter suas posições, ficando em desacordo sempre que desejarem. Não é necessário que haja um acordo sempre sobre todos os pontos abordados. Muitas vezes, mesmo em desacordo sobre pontos específicos, uma parte percebe que, embora o que foi acordado não seja o melhor para sua posição inicial, é o que é possível construir no processo e, nestes casos, registra sua discordância sem inviabilizar o processo em si. É o acordo possível, e não o acordo perfeito, que é buscado no processo.

A cooperação é um elemento que deve permear todo o desenvolvimento do processo, pois assim a competição entre as partes vai sendo gradativamente eliminada. Para que a colaboração seja efetiva, as partes devem ter o mesmo espaço e importância no processo, com as mesmas possibilidades de externar suas visões na construção da solução. Assim, as partes acabam percebendo, no transcorrer do procedimento, que sua atenção vai se concentrando nos pontos comuns e relevando para segundo plano as divergências.

O ideal é que as decisões do procedimento sejam tomadas através de convencimentos, e não de métodos adversariais, como a adoção de votações ou persuasão. Mediante o convencimento livre, as partes vão sendo incluídas no processo de construção do acordo. No entanto, nada obsta que as próprias partes adotem o procedimento de votação como premissa, visando demonstrar o consenso da maioria e a pontual discordância de alguns com os pontos específicos abordados no processo.

Deve-se buscar sempre a construção de uma posição unificada, consensual, edificada pelo convencimento efetivo das partes envolvidas, mas nada obsta que tal consenso seja produzido mediante decisões majoritárias, desde que aqueles que forem vencidos entendam a importância do processo e o mantenham íntegro, apesar de não concordarem com uma ou outra decisão tomada.

A inclusão das partes não é incompatível com a preservação de sua independência, de modo que a parte pode se sentir incluída no processo, em alguma etapa, simplesmente com a anotação de seu posicionamento divergente que ela, para preservar sua autonomia, quer registrar.

Tratando de conflitos complexos sobre os quais se debruçam diversos olhares distintos, o processo de construção de consensos deve compreender, adequadamente, as posições, interesses e valores que gravitam em torno do problema. As posições se referem ao que cada parte quer extrair do conflito. Os interesses são os motivos que explicam porque as partes querem extrair exatamente aquela posição do conflito. Os valores, por sua vez, são os fundamentos que explicam qual a importância de se conseguir algo específico tem para cada parte.

Mediante a compreensão das posições, interesses e valores de cada parte é possível ter uma dimensão mais aproximada, mais real, dos pontos que realçam os conflitos entre elas. Suas diferentes visões ficam evidenciadas, os motivos que sustentam as diferentes percepções também e, ainda, quanto cada um está disposto a abrir mão para obter um resultado mais satisfatório do processo. 
Assim, aumenta a possibilidade de buscar construir soluções mais consentâneas com as necessidades e interesses de todos os envolvidos. Como foi dito, não a solução perfeita, mas a solução possível diante da complexidade dos problemas enfrentados.

O processo, além de ter a efetiva possibilidade de construir soluções adequadas para o conflito, também pode ter repercussão sobre a própria relação das partes envolvidas. Através de uma intensificação do diálogo, as partes, inicialmente antagônicas, podem estabelecer uma relação de confiança recíproca, superando suas diferenças, embora continuem a respeitar suas individualidades divergentes. O processo pode então transformar as relações entre os atores, fazendo com que eles passem de uma posição de antagonismo generalizado e aparentemente insuperável, para uma posição de consenso possível ante a compreensão, por cada um, de que o consenso gerado é melhor do que a manutenção das divergências.

Como o diálogo é intensificado, a confiança vai sendo construída e essa construção acaba gerando mais diálogo, em um círculo positivo de entendimento.

Basicamente, o processo de construção de consensos se desdobra em três fases, que são a fase pré-negocial, a negocial e a pós-negocial.

A fase pré-negocial cuida da instalação do processo, provocada por um dos atores envolvidos. Nessa fase é feita a proposta de busca de solução negociada para os conflitos identificados. Cumpre ao facilitador (que pode ser o próprio proponente do processo) identificar os conflitos e os atores envolvidos, levantar o entendimento individual e grupal sobre os problemas, e verificar quais tentativas já foram realizadas para superar os conflitos, quais foram bem ou malsucedidas, tentando assim alcançar, pelo processo a ser iniciado, o maior número de atores diretamente relacionados com as possibilidades de enfrentamento e resolução dos problemas, visando conferir maior legitimidade a decisão final.

$\mathrm{Na}$ fase pré-negocial o facilitador deve construir uma agenda dos trabalhos, estabelecer as regras de reunião e, se for o caso de deliberação para tomadas de decisão (protocolo), identificar a necessidade de convidar especialistas para contribuir com o processo.

Na fase negocial caberá ao facilitador estimular a participação das partes na demonstração de suas posições, interesses e valores. Nessa fase são expostos os conflitos, as diversas visões sobre eles e, a partir deste desenho inicial, as partes passam a dialogar, expondo seus convencimentos sobre os problemas.

A partir do avanço desse processo já será possível esboçar alguma proposta definitiva de construção de consenso. Já se poderá estabelecer o rumo das negociações, os pontos divergentes mais significativos e sobre os quais deverá se concentrar a busca de convencimento.

Todo esse processo, baseado na confiança entre os participantes, poderá incluir a apresentação de textos, documentos, informações variadas, apresentações, etc. Poderão ainda as partes fixarem, de forma definitiva, os eixos de decisão, ou seja, os pontos essenciais sobre o processo deliberativo final. Ao facilitador caberá, ao final desta fase, condensar as discussões em um documento único, claro e objetivo a ser repassado aos demais atores, que sobre ele se debruçarão e fixarão suas posições de acordo.

Estruturada a proposta de acordo, passa-se a fase pós-negocial que está direcionada a implementação do que fora decidido. Nessa fase o facilitador deve formalizar o acordo, ou seja, transformar as decisões informais em decisões formais, estabelecer um mecanismo de acompanhamento de implementação das decisões que não inviabilize futuras renegociações, deixando sempre aberta a possibilidade de rediscussão do que fora decidido.

Em linhas gerais, o processo de construção de consensos possui os mesmos elementos essenciais de qualquer atividade coletiva, participativa e deliberativa, que é despertar confiança e interesse, saber ouvir, cooperar, respeitar e buscar soluções criativas e inovadoras para conflitos complexos que exigem, no processo de tomada de decisões, um elevado grau de legitimidade democrática. 
A construção de consensos, atuando como mecanismo próprio de resolução de consensual de conflitos entre múltiplas partes, é uma metodologia que consolida a democracia, criando espaços públicos de deliberação, institucionalizando as regras do jogo com a finalidade de criar consensos em diversas e variadas situações, em que os atores tomam em suas mãos, com legitimidade, a responsabilidade de construir soluções adequadas que, provenientes de uma convivência harmoniosa e respeitosa, possa manter um grau positivo de relacionamento entre eles para o futuro.

No entanto, em muitos casos, as barreiras impostas à busca de soluções por meio do consenso são difíceis de serrem transpostas. Em uma sociedade acostumada ao litígio, acomodada na crença de que suas disputas devem ser sempre resolvidas de forma adversarial, como ocorre hoje com a sociedade brasileira, muitas organizações, públicas e privadas, ignoram a possibilidade consensual de resolução de seus problemas e preferem o caminho da imposição, ou da resistência.

Quase sempre se aposta em disputadas judiciais que, em sua maioria, incluem o poder público, porque a abertura democrática, que promove discussões abrangentes e participativas, não é algo que conte com a adesão de muitos governantes, que preferem o exercício puro e simples do poder, da relação de força política como fundamento de imposição de suas decisões.

O processo de construção de consensos pode ser obstado, ou muito prejudicado, por diversos fatores, mas principalmente pela falta de transparência do processo, pelo fluxo não otimizado da troca de informações, pela diversidade de assuntos que devem ser abordados e, principalmente, pela falta de comprometimento das partes com a construção de uma ambiência de cooperação e responsabilidade recíprocas.

Christopher Moore e Peter Woodrow (1999) indicam quais as situações adequadas ou não à resolução por meio da construção de consenso. Segundo esses autres, são adequados à construção de consenso os casos em que nenhum indivíduo do grupo tem autoridade para decidir a questão unilateralmente, pois a autoridade/poder de uma só parte impede a construção equânime de um consenso; quando todos os indivíduos ou grupos possuem o mesmo conhecimento sobre a questão - informações privilegiadas conferem poder demasiado a uma parte dando espaço à persuasão; quando as partes são divergentes, mas sinalizam para uma possível conciliação de interesses e de valores; quando o sentimento de união prevalece, mesmo consideradas as diferenças; quando há necessidade de cooperação mútua para se implementar decisões, e quando as partes que buscam a solução para o conflito acreditam na integração e nas decisões construídas pelo diálogo.

Por outro lado, a construção de consenso não é indicada quando a decisão já foi tomada e a tentativa de construir consenso é inútil. Há situações em que fica claro que cada parte pode resolver os problemas por si, sem precisar dos outros. O mesmo pode ocorrer quando o assunto não é muito importante e, por isso, não compensa toda a energia e o esforço necessários para realizar um processo de construção de consenso, ou quando pessoas ou grupos cruciais para a decisão se recusam a participar do processo.

\section{A construção de consensos em conflitos socioambientais}

Conflitos socioambientais, como já demonstrado, são conflitos complexos e que envolvem diferentes atores. São, portanto, conflitos que, por sua própria natureza, indicam a aplicação do método de construção de consensos para a sua resolução consensual.

Ademais, para resolver casos com complexa conflituosidade, assim definidas pela natureza dos interesses em disputa, o mecanismo da construção de consensos pode obter melhores resultados do que as tentativas tradicionalmente utilizadas, porque decisões de ordem política ou judicial, estabelecidas verticalmente, tem demonstrado que não foram capazes de resolver, com eficiência, conflitos socioambientais importantes. 
Atuações políticas e judiciais são geralmente demoradas e agregam custos financeiros elevados para sua efetivação e, mais importante, sua decisão não satisfaz todas as partes em conflito, além de incentivar os litigantes a se concentrarem em detalhes técnicos-jurídicos e procedimentais ao invés de tratarem de questões mais substanciais, diretamente relacionadas com as causas reais do conflito.

A substituição de decisões verticais pela sistemática horizontal, que iguala todos os envolvidos, parece ser o caminho certo a seguir, ou pelo menos a ser tentado.

O mecanismo de construções de consensos aplicado à resolução de conflitos socioambientais desempenha tarefas importantes, como a identificação de representantes de todas as partes envolvidas no conflito, os grupos afetados pelas decisões tomadas, além de garantir a participação efetiva desses atores em todas as fases da negociação.

Além disso, o método define uma agenda de trabalhos, especificando os pontos convergentes e divergentes para, sobre estes, abrir as tratativas de acordo, cuja concretização é incentivada através de múltiplas reuniões, discussões de soluções inovadores ainda não tentadas, fixando um olhar prospectivo sobre o conflito, resolvendo-o no presente, mas, acima de tudo, evitando que volte a se repetir no futuro, funcionando com ótimo instrumento de prevenção de danos ambientais.

Sempre que se busca resolver conflitos socioambientais com a utilização do mecanismo de construção de consensos, o que se pretende, na realidade, é a criação de um espaço público plural, integrado por diversas instituições representativas de diferenciados setores da sociedade, na esfera pública e privada, todas atuantes na temática proposta, com o objetivo de, promovendo a efetiva interação entre as diversas visões sobre os conflitos existentes, conseguir extrair um consenso possível a ser materializado em uma proposta capaz de subsidiar os estudos técnicos já produzidos sobre a situação em litígio, conferindo um panorama mais seguro, estável e confiável para a tomada de decisão, seja empresarial, seja governamental. Trata-se, portanto, de uma abertura no processo de tomada de decisão, ou seja, de uma tentativa de conferir maior democratização e legitimidade ao ato final decisório.

Em conflitos socioambientais, a criação de instrumentos de gestão ambiental quase sempre é definida mediante a elaboração de políticas públicas e, como é óbvio, políticas públicas quase sempre não são formuladas de forma coerente, pois decorrentes de diversas visões controvertidas sobre um mesmo tema. A partir do momento em que estas diversas visões dialogam, aproximam-se as partes envolvidas na obtenção de um melhor resultado decisório, pois, conforme enfatiza Maria Paula Dallari Bucci (2006), pensar em política pública é buscar a coordenação entre os poderes públicos e entre as várias pastas do governo, considerando, ainda, a interação entre organismos da sociedade civil e o Estado. Por esse motivo, tem crescido a importância de instrumentos consensuais na gestão pública, como os convênios e os consórcios.

Na verdade, o mecanismo de construção de consensos demonstra sua perfeita adequação para tratar de conflitos de natureza socioambiental que, por sua complexidade, exigem a interferência, participação e cooperação de múltiplas partes. Trata-se de uma técnica capaz de democratizar o processo de construção de políticas públicas, quase sempre adotadas de forma verticalizada, a partir de uma estrutura de poder, e que acirra ao invés de compor adequadamente o conflito.

Já existem experiências exitosas no Brasil, embora embrionárias, de definição de políticas públicas com a utilização de mecanismos de construção de consensos, sendo exemplos a gestão de recursos hídricos e iniciativas de elaboração de orçamentos participativos.

Um aspecto fundamental que deve ser considerado é que um amplo processo participativo na formulação de políticas públicas, além de conferir legitimidade à decisão final, a estabiliza no tempo, visto que o consenso sobre ela formado torna aquela política pública muito menos vulnerável a alterações advindas da troca do poder político por sucessivas alternâncias eleitorais.

A construção de consensos, concebida como um instrumento autônomo de composição consensual de conflitos abrangendo diversas partes interessadas, revela-se como mecanismo satisfatório de 
aperfeiçoamento de processos decisórios complexos que buscam, diretamente, maior grau de aceitação perante a sociedade, ou seja, que necessitam de uma maior legitimidade, pacificando a situação atual e futura das partes inicialmente em conflito, e solidificando a aceitação das decisões tomadas.

Trata-se de um modelo eficaz e democrático, de busca de soluções mais harmônicas, cooperativas e participativas. Adotando decisões de forma horizontal, a sociedade se sente partícipe, representada e integrante do processo. Na esfera pública, o governante abre a possibilidade de cooperação que, ao final, acaba por protegê-lo das possíveis intervenções de fortes grupos de interesses que lutam para impor sua visão única sobre os conflitos vivenciados.

O Direito, por sua vez, cumpre um papel fundamental na construção dessa modelagem, pois avaliar as condições decisórias sobre a formulação de políticas públicas pode ser tarefa realizada a partir do Direito, e não apenas da Ciência Política. Portanto, o que se propõe é a construção e consolidação do mecanismo de construção de consensos como um modelo de análise que dê conta da complexidade das relações sociais próprias do estado contemporâneo de direito, além de atuar como um modelo que preste um auxílio na busca de novas, eficazes e eficientes formas de participação popular e democrática.

O que se tenciona finalmente demonstrar é que, em casos de conflitos socioambientais, o mecanismo de construção de consensos é apto a atuar de forma proativa, voluntária, aberta, democrática e tecnicamente fundada, buscando construir entre atores inicialmente divergentes uma ambiência de cooperação em torno de um objetivo que é entender adequadamente os conflitos, sua complexidade, suas especificidades e as diversas visões sobre eles para, a partir desse ponto, trabalhar na maximização dos consensos, na superação de antagonismos e na concretização de acordos possíveis que melhorem a situação inicial de todos os envolvidos.

Em matéria ambiental, em que ocorre com intensidade significativa a interação da sociedade civil organizada com o setor governamental, tal alternativa de construção consensual de conflitos é positiva e deve sempre ser buscada e incentivada, bastando apenas que esse arranjo institucional seja aperfeiçoado metodologicamente, de forma a se impor como uma forte ferramenta de resolução de conflitos complexos, como são, especialmente, os de natureza socioambiental.

\section{Conclusão}

As questões que envolvem a proteção do meio ambiente e a construção do desenvolvimento sustentável requerem uma análise profunda sobre as nuances da gênese de tais problemas, sobre asposições interesses e valores avaliados, e a exata identificação das partes envolvidas.

O conceito de meio ambiente requer compreensão sistêmica dos elementos que o integram - físico, cultural e patrimonial. A construção real e efetiva do desenvolvimento sustentável requer a compreensão e a prática equilibrada do crescimento das atividades econômicas e da proteção ambiental. Toda essa complexidade resulta em conflitos específicos, com interesses e valores próprios, que passam a requerer, pelas especificidades que apresentam, a utilização de mecanismos de solução que satisfaçam todas as partes envolvidas.

A construção de consensos, a partir de estudos desenvolvidos pelo professor Lawrence Susskind, apresenta-se como meio inclusivo, participativo e baseado no diálogo, capaz de compreender a profundidade e complexidade apresentada pelas questões socioambientais e promover uma comunicação que permita a construção de soluções que pacifiquem as relações entre todos os envolvidos.

A construção de consenso embasa-se no reconhecimento das diferenças, na possibilidade de manter-se em desacordo, no diálogo colaborativo, na metodologia de inclusão, na percepção e distinção das posições, dos interesses e valores.

Mecanismo inovador de resolução de conflitos que estimula a comunicação entre as partes envolvidas, a construção de consensos é capaz de promover decisões participativas, inclusivas e consensuadas 
dos problemas, apresentando-se como parâmetros de justiça e de utilidade social. A utilização desse específico mecanismo para prevenir e/ou solucionar questões de ordem socioambiental pode trazer grandes benefícios para toda a sociedade, evitando inclusive atos autoritários e reações violentas, os quais têm marcado o panorama de tal conflituosidade no Brasil.

\section{Referências}

ALMEIDA, Tânia; ALMEIDA, Rafael Alves de. Construção de consenso - um instrumento contemporâneo e democrático para a formatação de políticas públicas. In: BRAGA NETO, Adolfo; SALES, Lilia Maia de Morais (Org.). Aspectos atuais sobre a mediação e outros métodos extra e judiciais de resolução de conflitos. Rio de Janeiro: GZ, 2012. p. 314-330.

BINGHAM, Gail. What is consensus building and why is it important for resource management? 2011. Disponível em: <http://www.resolv.org/wp-content/uploads/2011/02/Consensus-Building.pdf> Acesso em: 15 maio 2016.

BRASIL. Conselho Nacional de Justiça. Justiça em números 2015: ano-base 2014. Brasília: CNJ, 2015. BUCCI, Maria Paula Dallari (Org.). Políticas públicas - Reflexões sobre o conceito jurídico. São Paulo: Saraiva, 2006.

CRESPO, Mariana Hernandez. Building the Latin America we Want: Supplementing representative democracies with consensus-building. 2008. Disponível em: <http://cardozojcr.com/vol10no2/425-490. pdf>. Acesso em: 23 maio 2016.

LAUTIER, Bruno. O consenso sobre as políticas sociais na América Latina, negação da democracia? 2010. Disponível em:<file:///C:/Users/usuario/Desktop/artigos\%20tese/O\%20 CONSENSO\%20SOBRE\%20AS\%20POLÍTICAS\%20SOCIAIS\%20NA\%20AMÉRICA.pdf>. Acesso em: 15 ago. 2016.

LIBISZEWSKI, Stephan. What is an environmental conflict? Zurich: Center for Security Studies,1992.

LITTLE, Paul E. Os conflitos socioambientais: um campo de estudo e de ação política. In: BURSZTYN, M. (Org.). A difícil sustentabilidade: Política energética e conflitos ambientais. Rio de Janeiro: Garamond, 2002. p.107-122.

MARTÍNEZ ALIER, Juan. O ecologismo dos pobres: Conflitos ambientais e linguagem de valoração. São Paulo: Contexto, 2007.

MATTOS, Paulo Todescan Lessa. O novo Estado regulador no Brasil - Eficiência e legitimidade. São Paulo: Singular, 2006.

MOORE, Christopher W.; WOODROW, Peter J. Collaborative problem solving whithin organizations. Califórnia: SAGE Publications, 1999.

RED MESOAMERICANA DE MANEJO DE CONFLICTOS SOCIOAMBIENTALES. Conflictos socioambientales em América Latina: Uma visíon desde la Red Mesoamericana de manejo de conflictos socioambientales. Costa Rica: Universidade para la Paz, 1999.

SALES, Lilia Maia de Morais; VASCONCELOS, Mônica Carvalho. Mediação familiar: um estudo histórico-social das relações de conflito nas famílias contemporâneas. Fortaleza: Expressão Gráfica e Editora Ltda., 2006.

SALES, Lilia Maia de Morais. Mediare, um guia prático para mediadores. 3. ed. Rio de Janeiro: GZ, 2010.

SHMUELI, Deborah; VRANESKY, Ariella. A mediação ambiental nas relações internacionais. In: HERZ, Monica; SIMAN, Maíra; DRUMOND, Paula (Org.). Mediação internacional. Petrópolis/ Rio de Janeiro: Vozes/ Puc-Rio, 2016.

SUSSKIND, Lawrence; CRUIKSHANK, Jeffrey. Breaking the impasse: consensual approaches to resolving public disputes. New York: Basic Books, 1987. 
TURNER, Matthew D. Political ecology and the moral dimensions of "resource conflicts": the case of farmer-herder conflicts in the Sahel. Political Geography, Amsterdam, v. 23, n. 7, p. 863-889, 2004.

Recebido em: 26/08/2016.

Aprovado em: 27/09/2016. 